\title{
Antibody Functionalised Gold Nanoprobes Based Colorimetric Assay for the Direct Detection of Phenylurea Herbicide
}

\author{
Priyanka Sharma, Bipul Kumar \& C. Raman Suri (Corresponding author) \\ Institute of Microbial Technology (CSIR) \\ Sector 39-A, Chandigarh 160036, India \\ Tel: 91-172-666-5225Ｅ-mail: raman@imtech.res.in
}

$\begin{array}{ll}\text { Received: October 10, } 2011 & \text { Accepted: November 2, } 2011 \quad \text { Published: January 1, } 2012 \\ \text { doi:10.5539/ep.vln1p12 } & \text { URL: http://dx.doi.org/10.5539/ep.vln1p12 }\end{array}$

Priyanka Sharma and Bipul Kumar contributed equally.

The research is financed by ILTP Programme No ILTP/A-1.29

\begin{abstract}
One-step homogeneous colorimetric immunoassay format for direct detection of herbicide diuron is reported. Gold nanoparticles $(30 \mathrm{~nm})$ functionalised with specific anti-diuron antibody was used as bioprobes for the development of non-crosslinking hybridization method, where aggregation of the gold-nanoprobes is induced by an increasing salt concentration, and is prevented by the amount of antigen (diuron) present in sample solution. The aggregation profile of the antibody functionalised gold nanoparticles directed by the immunoreaction was investigated using transmission electron microscopy (TEM), dynamic light scattering (DLS) and was further confirmed colorimetrically by measuring the change in the absorption ratio $(620 / 520 \mathrm{~nm})$ with increasing amounts of diuron. The assay exhibited an excellent sensitivity and specificity based on absorbance profile showing the dynamic response range from $0.1-50 \mathrm{ng} / \mathrm{mL}$ for diuron with a detection limit of $\sim 5 \mathrm{ng} / \mathrm{mL}$. The new technique could be used for fast, high-throughput screening of pesticides in environmental diagnostics at a very low cost.
\end{abstract}

Keywords: Colorimetric immunoassay, Gold nanoparticles, Aggregation, Diuron

\section{Introduction}

Gold nanoparticles have been investigated widely for their potential applications in biomolecular detection because of their size dependent unique electronics or optical properties (Mirkin, 2000; Reynolds et al., 2000). These nanoparticles have emerged as important colorimetric reporters because of their high extinction coefficients and strongly distance dependent optical properties (Huang et al., 2005; Chen et al., 2008). These colloidal particles have been explored for their potential applications in the development of single-step homogeneous immunoassay formats (Otsuka et al., 2001). A non-crosslinking hybridization method, where aggregation of the gold-nanoprobes is induced by an increasing salt concentration, has recently been reported to detect eukaryotic gene expression without retro-transcription or PCR amplification (Baptista et al., 2006; Aryal et al., 2006). These assay formats using bio-functionalised gold nanoparticles probes offered several advantages over conventional heterogeneous assay formats with respects to sample preparation, good stability, easy-to-use and inexpensive.

Diuron (3-(3,4-dichlorophenyl)-1,1-dimethylurea), a substituted phenylurea herbicide, is used widely as a broad-spectrum pre-emergence weed control in a wide variety of crops (Tomlin, 1997). It is easily taken up from the soil by the root system of plants and rapidly translocated into their stems and leaves via xylem by transpiration. It functions primarily by inhibiting the Hill reaction in photosynthesis by limiting the production of high-energy compounds such as adenosine triphosphate (ATP) used for various metabolic processes (Bazot et al., 2007). Besides its use as herbicide, it is also employed as an active ingredient in antifouling boat paints and in algaecide formulations used in fountains and aquaculture (Sorensen et al., 2008). Due to the extensive use of diuron and other phenylurea herbicides, their residues are detected in ground and surface water in concentrations exceeding their permissible limits (Lapworth \& Gooddy, 2006; Eriksson et al., 2007). These herbicides have 
been shown to be endocrine disruptors, showing ecotoxic effects, and are known to make adverse effects on human health program (Tixier et al., 2001). It is relatively persistent in soil with a half-life of 3-6 months, which varies from several weeks to years in different types of environment (Giacomazzi \& Cochet, 2004; Louchart \& Voltz, 2007). To control such hazardous pollutants in the environment, a sensitive method of detection is needed.

Various analytical methods such as chromatography and mass spectrometry are currently been used for the determination of these pesticide residues in samples (Krämer, 1996; Liu et al., 2007; Scheyer et al., 2007). These assays, apart from being highly specific, exhibit the desired sensitivity and accuracy for the detection of low molecular weight pesticides present in the environment. Parallel to the above techniques, immunochemical assay using specific antibodies are gaining importance and becoming a preferential alternate approach for pesticide measurement in virtue of their selectivity, sensitivity and rapidness (Franek et al., 1994; Gabaldon et al., 1999; Brichta \& Franek, 2003; Kaur et al., 2008). In this paper, we propose a novel immunoassay format based on a non-cross-linking hybridization method, where aggregation of the antibody functionalised gold nanoparticles is induced by an increasing salt concentration. The presence of antigen (diuron) prevents aggregation of Ab-GNPs while its absence leads to aggregation, resulting in a visible change of color from red to blue. The analytical capabilities of the new assay format are discussed.

\section{Materials and Methods}

\subsection{Materials}

Gold chloride, monosodium glutamate, Freund's complete adjuvant (CFA), Freund's incomplete adjuvant (IFA), protein-A Sepharose, BSA-sepharose and goat anti-rabbit IgG-HRP conjugate were purchased from Sigma (India). 3, 3', 5, 5' tetramethylbenzidiene (TMB) was purchased from Bangalore Genei, India. The glassware used for synthesizing GNPs was thoroughly cleaned and siliconized using $1 \%$ 3-glycidoxypropyltrimethoxysilane solution (Sigma, India). Water used for making buffers and nanoparticles synthesis was purified with a Milli-Q ultra pure system (Millipore, India) having a resistivity $>18 \mathrm{M} \Omega / \mathrm{cm}$.

\subsection{Antibody Functionalised Gold Nanoprobe}

Specific anti-diuron antibody was produced in our lab by using a well characterized hapten-protein conjugate with optimum hapten density (Sharma et al., 2010). For this, young (4-6 weeks old) New Zealand white rabbits were immunized subcutaneously with $250 \mu \mathrm{g}$ of DCPU-BSA conjugate emulsified with Freund's complete adjuvant. Subsequently, three secondary boosters of the same dose (emulsified with IFA) were injected at intervals of 21 days. The rabbits were bled on the fifth day after each booster, and the antibody titer was determined by ELISA. Immunoglobulin G (IgG) fractions were purified from the sera using a protein-A Sepharose column as per the instructions given in the product catalogue. The eluted IgG fractions were pooled and subsequently dialyzed against phosphate buffer saline (PBS) for $36 \mathrm{~h}$. The purified antibody was stored at $-20{ }^{\circ} \mathrm{C}$ The eluted antibody was further purified by passing through BSA-Sepharose column to remove anti-BSA antibody fractions.

For making antibody functionalized nanoprobes, an aqueous solution of gold nanoparticles $(30 \mathrm{~nm})$ was prepared by reducing tetrachloroauric acid $\left(\mathrm{HAuCl}_{4}\right)$ with glutamic acid under refluxing condition to yield colloidal gold particles, as described previously (Wangoo et al., 2008). In brief, aqueous solution of GNPs was prepared by taking $50 \mathrm{ml}$ of $0.01 \%$ tetrachloroauric acid in Milli-Q water and refluxed for 10 min with $50 \mathrm{ml}$ aqueous solution of glutamic acid $(15 \mathrm{mM})$ yielding GNPs $\left(\mathrm{Au}^{0}\right)$ as confirmed by the appearance of a dark cherry-red color of the solution. Colloidal gold solution was subjected to centrifugation and the conjugate was washed with deionized water to remove any uncoordinated glutamic acid. The synthesized GNPs were characterized by taking UV-Vis absorbance spectra using multimode microtiter plate reader (BioTek synergy 2, Finland). Their size was analyzed by Malvern size analyzer. The morphological studies of the GNPs were carried out using transmission electron microscope (TEM-Hitachi HD 2300A STEM) operating at $200 \mathrm{kV}$ accelerating voltage. TEM Samples were prepared by placing a drop of GNPs solutions on carbon-coated grids and were allowed to dry for 20 min at room temperature before analysis. The synthesized GNPs were conjugated with antibodies and further characterized by XPS (Omicron ESCA Probe) equipped with He-Ne Laser $(633 \mathrm{~nm})$ having high sensitivity to the chemical structures near the outmost of the surface $(0.5-8 \mathrm{~nm})$.

For preparing antibody nanoprobes, anti-diuron antibodies $(100 \mu \mathrm{g} / \mathrm{mL})$ prepared in phosphate buffer were added into $1 \mathrm{~mL}$ colloidal gold solution under mild stirring condition. The $\mathrm{pH}$ of the colloidal gold solution was maintained at 7.4 by addition of dilute $0.1 \mathrm{M} \mathrm{K}_{2} \mathrm{CO}_{3}$ before adding antibody. The mixture was incubated overnight at $4{ }^{\circ} \mathrm{C}$ and centrifuged at $12,000 \mathrm{rpm}$ for $30 \mathrm{~min}$ to remove traces of unconjugated antibody. The pellet obtained was further washed twice with $10 \mathrm{mM}$ Tris $(\mathrm{pH} 8.0)$ containing $3 \%$ BSA. The pellet was 
resuspended in $1 \mathrm{~mL}$ of phosphate buffer $(20 \mathrm{mM}, \mathrm{pH} 7.4)$ and stored at $4{ }^{\circ} \mathrm{C}$. The conjugate was subjected to characterization using UV-Vis spectrophotometer (Hitachi 2800).

\subsection{Colorimetric Immunoassay for Diuron}

The homogeneous immunoassay based on colorimetric detection was conducted by diluting antibody functionalised nanoparticles solution (1:1 dilution) in water. $(50 \mu \mathrm{L})$ of this solution was taken into each well of micro titre plate (Nunc, USA). Antibody concentration was first optimised by adding $50 \mu \mathrm{L}$ of hapten-protein conjugate added to $50 \mu \mathrm{L}$ of antibody functionalised GNPs (tracer) solution (different concentrations) and mixed. After giving 10 minutes incubation time $5 \mathrm{M} \mathrm{NaCl}$ was added to induce aggregation. Aggregation profile was measured using multimode microtiter plate reader (Biotek, Synergy 2). For competitive inhibition assay format, $50 \mu \mathrm{L}$ of conjugate (DCPU-BSA) was first mixed with same volume of standard diuron samples of different concentrations (1-100 ng/mL prepared in DDW). In the solution, $50 \mu \mathrm{L}$ of antibody functionalised GNPs solution (tracer) was added and kept for incubation at room temperature for $10 \mathrm{~min}$. After incubation, $5 \mathrm{M} \mathrm{NaCl}$ was added to induce aggregation followed by measuring the aggregation profile $(620 / 520 \mathrm{~nm})$. Three measurements were recorded and accordingly, the standard deviation was calculated. The data was normalized by $\% \mathrm{~B} / \mathrm{B}_{0}$ transformation and the specific hapten concentration yielding $50 \%$ inhibition $\left(\mathrm{IC}_{50}\right)$ was used to calculate the cross reactivity.

\section{Results and Discussion}

\subsection{Development of Antibody Functionalized GNPs as Bioprobes}

For preparing well characterized antibody functionalized gold bioprobe, an aqueous solution of GNPs was prepared by reducing tetrachloroauric acid $\left(\mathrm{HAuCl}_{4}\right)$, with glutamic acid under refluxing to yield colloidal gold particles, as described previously by our group. In the synthesis route, reduction of $\mathrm{HAuCl}_{4}$ occurred through the transfer of electrons from the amine group of glutamic acid to the $\mathrm{Au}^{3+}$ ion leading to the formation of $\mathrm{Au}^{0}$. This metallic gold then nucleates and grows to form gold nanoparticles, and is subsequently capped and stabilized by the amino acid. Figure 1 shows the UV-Vis spectra of gold nanoparticles and antibody functionalized gold nanoprobes. Inset of figure 1 revealed that $100 \mu \mathrm{g} / \mathrm{mL}$ antibody concentration selected for binding with GNPs was optimum since the observed antibody peak (unbound fraction) at $280 \mathrm{~nm}$ was almost negligible. TEM images further confirmed that the size of the synthesized GNPs using optimum concentration of glutamic acid was $\sim 30 \mathrm{~nm}$ (Figure 2). Binding of antibody to GNPs was established through electrostatic interaction or ionic/hydrogen bonding between the surface-terminated anionic groups $\left(-\mathrm{COO}^{-}\right)$on the nanoparticles and the positively charged amino groups $\left(-\mathrm{NH}^{+3}\right)$ of the lysine residues of the protein. The corresponding XPS spectra of the GNP solutions without antibody labeled and with antibody labeled are presented in figure 3. A single gold ( $\mathrm{Au} 4 \mathrm{f} 7 / 2$ ) peak at $84 \mathrm{eV}$ was observed clearly demonstrating that all of the $\mathrm{Au}^{+3}$ ions used in the process were reduced to $\mathrm{Au}^{0}$ by glutamic acid. Two distinct sulfur peaks (S $2 p$ and S $2 \mathrm{~s}$ ) were observed at 168 and $230 \mathrm{eV}$ representing distinct sulfur entities present in cysteine or lysine residues of antibody which are used for binding to gold nanoparticles. The nitrogen $1 \mathrm{~s}$ peak observed at $400 \mathrm{eV}$ is likely due to unionized, non-protonated nitrogen (Kumar et al., 2000). This is in agreement with earlier studies reported on the adsorption of proteins/amino acids or amines on gold surfaces (McMillan et al., 2001). Therefore, we speculate that antibody may bind to gold nanoparticles through $-\mathrm{NH}_{2}$ functionalities via pseudo-covalent interaction.

\subsection{Colorimetric Immunoassay for Diuron}

In general, gold nanoparticles tends to aggregate when the inter-particle distance of these GNPs decreases to less than approximately the average particle diameter by changing the surface properties of GNPs turning the color of the aggregates from red to blue. In this work, we demonstrate a simple one-step colorimetric detection approach based on competitive inhibition immunoassay method, where aggregation of the nanoprobes is induced by an increasing salt concentration. The presence of hapten-protein conjugate (DCPU-BSA) prevented aggregation and the solution remained red. However, binding of antigen (diuron) to the antibody functionalized GNPs bioprobe unstabilised the nanoprobe in solution, causing aggregation and the solution gradually turns blue with increasing concentration of antigen. The mechanism of electrolytic mediated aggregation of nanoprobes in presence or absence of antigen is shown in the scheme 1. Color change upon aggregation of nanoprobes is corroborated by visible spectra, where an intense plasmon resonance appeared within $600-650 \mathrm{~nm}$, with a concomitant decrease of the intensity of the original plasmon resonance at $520 \mathrm{~nm}$ (Payne et al., 2006; Wangoo et al., 2010). In the gold nanoparticles based bioprobes functionalized with specific antibody, the SPR band broadened and red shifted with an increased aggregation size. The gold nanoparticle aggregates showed a substantial decrease of the SPR band at $520 \mathrm{~nm}$, along with the development of a broad new band at $620 \mathrm{~nm}$ (Shuford et al., 2005). Upon addition of $\mathrm{NaCl}$ aqueous solution to the antibody complex, the color of the gold colloids gradually changed 
from red to blue, indicating the aggregation. It is attributed that in the electrolyte-induced aggregation of AuNPs, the interparticle distance becomes shorter and consequently electromagnetic coupling between the surface plasma modes of adjacent nanoparticles is feasible. Depending on the size of individual nanoparticles or the size of aggregates, the interaction can be dipolar or multipolar, resulting in surface plasmon resonance band broadening, red-shifting, and even splitting into two distinct bands (a visible band corresponding to the transverse mode and a near-IR band corresponding to the longitudinal mode).

Figure 4 shows the change in the absorbance ratio profile for $30 \mathrm{~nm}$ size GNPs labelled with anti-diuron antibody after the addition of $5 \mathrm{M} \mathrm{NaCl}$ with increasing amounts of antigen (diuron, monuron, fenuron) and fixed amount of hapten-protein conjugate. The aggregation ratio of antibody functionalised nanoprobes was gradually increased upto $0.82,0.80$ and 0.78 for monuron, diuron and fenuron respectively as their concentration was increased. For the antibody labelled gold nanoparticle assemblies, the aggregation size controlled the optical properties of the assemblies. This aggregation profile of gold nanoprobes was also analysed by TEM and DLS techniques (Figure $2 \mathrm{a}-\mathrm{c}$ ) which confirmed the variation in size of gold nanoparticles with the addition of increasing amounts of the antigen (diuron). For gold colloids the intensity of the $520 \mathrm{~nm}$ band decreases, suggesting the decrease of the numbers of isolated AuNPs. In contrast, a broad band appears between 600 and $800 \mathrm{~nm}$. The appearance of this near-IR band normally indicates that the geometry of nanoparticles in the aggregates changes, causing a "shunting" of dipole-dipole interaction and an initiation of quadruple interactions due to conductive contact. In such a case, the transverse and longitudinal polaritons produce non-equivalent resonance, with a broadening and red shifting of the longitudinal resonance, while the transverse resonance remains almost unchanged (Atay et al., 2004; Bellino et al., 2004).

\section{Conclusion}

In summary, we demonstrated here a simple one-step homogeneous immunoassay format based on colorimetric detection method for phenylurea herbicide diuron. Results can be assessed without the need of further signal enhancement or complicated technological solutions, which are common with other nanoparticles based methodologies. The method presented here proved to be selective, sensitive and inexpensive, as the overall cost for analysis is very low. The assay does not involve any washing cycle. Moreover, extremely small amounts of samples are needed for the assay (in this study, about $50 \mu \mathrm{L}$ sample solution was used for each assay). The proposed colorimetric method is very easy to perform, taking less than $15 \mathrm{~min}$, rendering it suitable for use at field applicable testing of toxic environment pollutants.

\section{References}

Atay, T. Song, J. H., \& Nurmikko, A. V. (2004). Nurmikko, Strongly interacting plasmon nanoparticle pairs: From dipole-dipole interaction to conductively coupled regime. Nano. Lett., 4(9), 1627-1631. http://dx.doi.org/10.1021/n1049215n

Aryal, S., Bahadur, R. K. C., Bhattarai, N., Kim, C. K., \& Kim, H. Y. (2006). Study of electrolyte induced aggregation of gold nanoparticles capped by amino acids. J. Colloid Interface Sci., 299(1), 191-197. http://dx.doi.org/10.1016/j.jcis.2006.01.045

Brichta, J., \& Franek, M.J. (2003). Identification of monoclonal antibodies against 2,4-D herbicide by ELISA and DNA sequencing. Agric. Food Chem., 51(21), 6091-6097. http://dx.doi.org/10.1021/jf0261093

Bellino, M. G., Calvo, E. J., \& Gordillo, G. (2004). Adsorption kinetics of charged thiols on gold nanoparticles. Phys. Chem. Chem. Phys., 6(2), 424-428. http://dx.doi.org/10.1039/b312252b

Baptista, P. V., Koziol-Montewka, M., Paluch-Oles, J., Doria, G., \& Franco, R. (2006). Gold-nanoparticle-probe-based assay for rapid and direct detection of Mycobacterium tuberculosis DNA in clinical samples. Clin. Chem., 52(7), 1433-1434. http://dx.doi.org/10.1373/clinchem.2005.065391

Bazot, S., Bois, P., Joyeux, C., \& Lebeau, T. (2007). Mineralization of diuron [3-(3,4-dichlorophenyl)-1, 1-dimethylurea] by co-immobilized Arthrobacter p. and delftia acidovorans. Biotechnol. Lett, 29(5), 749-754. http://dx.doi.org/10.1007/s10529-007-9316-7

Chen, S. J., Huang, Y. F., Huang, C. C., Lee, K. H., Lin, Z. H., \& Chang, H. T. (2008). Colorimetric determination of urinary adenosine using aptamer-modified gold nanoparticles. Biosens. and Bioelec., 23(11), 1749-1753. http://dx.doi.org/10.1016/j.bios.2008.02.008

Eriksson, E., Baun, A., Mikkelsen, P. S., \& Ledin, A. (2007). Risk assessment of xenobiotics in stormwater discharged to Harrestrup Å, Denmark. Desal., 215(1-3), 187-197. http://dx.doi.org/10.1016/j.desal.2006.12.008

Franek, M., Kolar, V., Granatova, M., \& Nevorankova, Z. (1994). Monoclonal ELISA for 2,4-D acid: 
characterization of antibodies and assay optimization. J. Agric. Food Chem., 42(6), 1369-1374. http://dx.doi.org/10.1021/jf00042a024

Gabaldon, J. A., Maquieira, A., \& Puchades, R. (1999). Current trends in immunoassays-based kits for pesticide analysis. Crit. Rev. Food Sci. Nutr., 39(6), 519-538. http://dx.doi.org/10.1080/10408699991279277

Giacomazzi, S., \& Cochet, N. (2004). Environmental impact of diuron transformation. Chemosphere, 56, 1021-1032. http://dx.doi.org/10.1016/j.chemosphere.2004.04.061

Huang, C. C., Huang, Y. F., Cao, Z., Tan, W., \& Chang, H. T. (2005). Aptamer-modified gold nanoparticles for colorimetric determination of platelet-derived growth factors and their receptors. Anal. Chem., 77(17), 5735-5741. http://dx.doi.org/10.1021/ac050957q

Krämer, P. M. (1996). Biosensors for measuring pesticide residues in the environment: past, present, and future. J. AOAC Int., 79(6), 1245-1254.

Kaur, J., Boro, R. C., Wangoo, N., Singh, K. R., \& Suri, C. R. (2008). Direct hapten coated immunoassay format for the detection of atrazine and 2,4-dichlorophenoxyacetic acid herbicides. Anal. Chim. Acta., 607(1), 92-99. http://dx.doi.org/10.1016/j.aca.2007.11.017

Kumar. A., Mukherjee, P., Guha, A., Adyantaya, S. D., Mandale, A. B., Kumar, R., \& Sastry, M. (2000). Amphoterization of colloidal gold particles by capping with valine molecules and their phase transfer from water to toluene by electrostatic coordination with fatty amine molecules. Langmuir, 16(25), 9775-9783. http://dx.doi.org/10.1021/la000886k

Lapworth D. J., \& Gooddy, D. C. (2006). Source and persistence of pesticides in a semi-confined chalk aquifer of southeast England. Environ. Pollut., 144(3), 1031-1044. http://dx.doi.org/10.1016/j.envpol.2005.12.055

Liu, J. F., Torang, L., Mayer, P., \& Jonsson, J. A. (2007). Passive extraction and clean-up of phenoxy acid herbicides in samples from a groundwater plume using hollow fiber supported liquid membranes. J. Chromatogr. A, 1160(1-2), 56-63. http://dx.doi.org/10.1016/j.chroma.2007.04.010

Louchart, X., \& Voltz, M. (2007). Aging effects on the availability of herbicides to runoff transfer. Environ. Sci. Technol., 41(4), 1137-1144. http://dx.doi.org/10.1021/es061186q

Mirkin, C. A. (2000). Programming the assembly of two- and three-dimensional architectures with DNA and nanoscale inorganic building blocks. Inorg. Chem., 39(11), 2258-2272. http://dx.doi.org/10.1021/ic991123r

McMillan, R., Meeks, B., Bensebaa, F., Deslandes, Y., \& Sheardown, H. (2001). Cell adhesion peptide modification of gold-coated polyurethans for vascular endothelial cell adhesion. J. Biomed. Mater. Res., 54(2), 272-283. http://dx.doi.org/10.1002/1097-4636(200102)54:2\%3C272::AID-JBM15\%3E3.0.CO;2-3

Otsuka, H., Akiyama, Y., Nagasaki, Y., \& Kataoka, K. (2001). Quantitative and reversible lectin-induced association of gold nanoparticles modified with $\alpha$-lactosyl- $\omega$-mercapto-poly (ethylene glycol). J. Am. Chem. Soc., 123(34), 8226-8230. http://dx.doi.org/10.1021/ja010437m

Payne, E. K., Shuford, K. L., Park, S., Schatz, G. C., \& Mirkin, C. A. (2006). Multipole plasmon resonance in gold nanorods. J. Phys. Chem. B., 110(5), 2150-2154. http://dx.doi.org/10.1021/jp056606x

Reynolds, R. A., Mirkin, C. A., \& Letsinger, R. L. (2000). A gold nanoparticle/latex microsphere-based colorimetric oligonucleotide detection method. Pure Appl. Chem., 72(1-2), 229-235. http://dx.doi.org/10.1351/pac200072010229

Shuford, K. L., Ratner, M. A., \& Schatz, G. C. (2005). Multipolar Excitation in Triangular Nanoprisms. J. Chem. Phys., 123(11), 114713-114721. http://dx.doi.org/10.1063/1.2046633

Scheyer, A., Briand, O., Morville, S., Mirasel, P., \& Millet, M. (2007). Analysis of trace levels of pesticides in rainwater by SPME and GC-tandem mass spectrometry after derivatisation with PFFBr. Anal. Bioanal. Chem., 387(1), 359-368. http://dx.doi.org/10.1007/s00216-006-0894-3

Sorensen, S. R., Albers, C. N., \& Aamand, J. (2008). Rapid mineralization of the phenylurea herbicide diuron by Variovorax sp. strain SRS16 in pure culture and within a two-member consortium. Appl. Environ. Microbiol., 74(8), 2332-2340. http://dx.doi.org/10.1128/AEM.02687-07

Sharma, P. S., Gandhi, S., Chopra, A., Sekar, N., \& Suri, C. R. (2010). Fluoroimmunoassay based on suppression of fluorescence self-quenching for ultra-sensitive detection of herbicide diuron. Anal. Chim. Acta., 676(1-2), 87-92. http://dx.doi.org/10.1016/j.aca.2010.07.042

Tomlin, C. (1997). The Pesticide Manual (11th ed.). British Crop Protection Council EU. 
Tixier, C., Sancelme, M., Bonnmoy, F. Cuer, A., \& Veschambre, H. (2001). Degradation products of a phenylurea herbicide diuron: Synthesis, ecotoxicity, and biotransformation. Environ. Toxicol. Chem., 20(7), 1381-1389. http://dx.doi.org/10.1002/etc.5620200701

Wangoo, N., Bhasin, K. K., Mehta, S. K., \& Suri, C. R. (2008). Synthesis and capping of water-dispersed gold nanoparticles by an amino acid: bioconjugation and binding studies. J. Colld. Inter. Sci., 323(2), $247-254$. http://dx.doi.org/10.1016/j.jcis.2008.04.043

Wangoo, N., Kaushal, J., Bhasin, K. K., Mehta, S. K., \& Suri, C. R. (2010). Zeta potential based colorimetric immunoassay for the direct detection of diabetic marker HbA1c using gold nanoprobes. Chem Com., 46(31), 5755-5757. http://dx.doi.org/10.1039/c0cc00224k

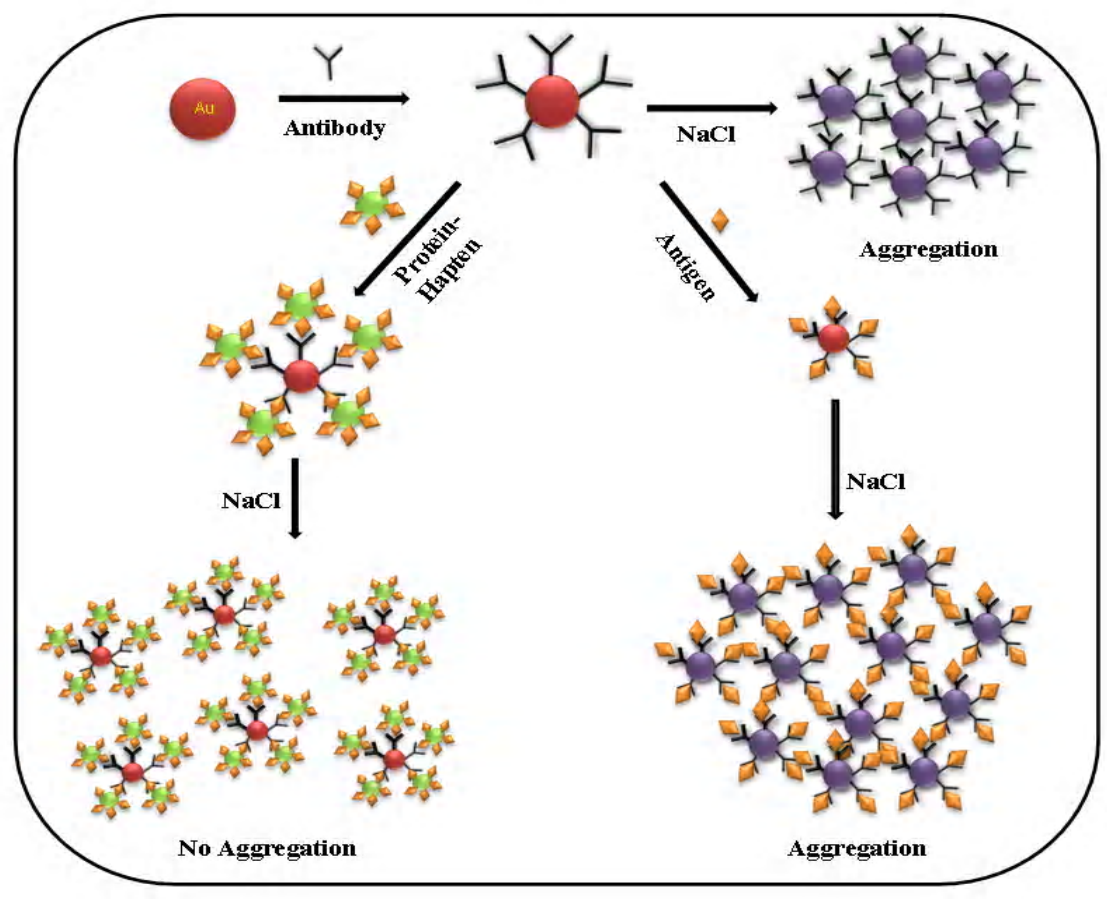

Scheme 1. The mechanism of electrolytic mediated aggregation of nanoprobes in presence or absence of antigen.

Color change upon aggregation of nanoprobes is corroborated by visible spectra, where an intense plasmon resonance appeared within $600-650 \mathrm{~nm}$, with a concomitant decrease of the intensity of the original plasmon resonance at $520 \mathrm{~nm}$

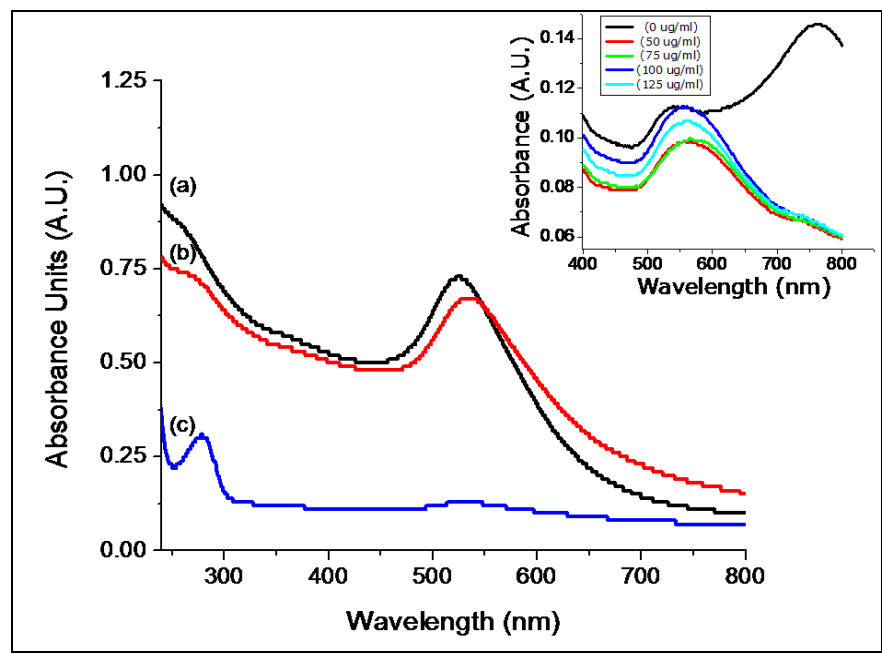

Figure 1. UV-Vis absorbance spectra of (a) gold nanoparticles (b) gold nanoparticles functionalized with antibody (c) free antibody (from the supernatant after centrifugation). Inset figure shows the different absorption spectra showing optimisation of optimum concentration of antibody $(0-125 \mu \mathrm{g} / \mathrm{ml})$ immobilized on gold nanoparticles 


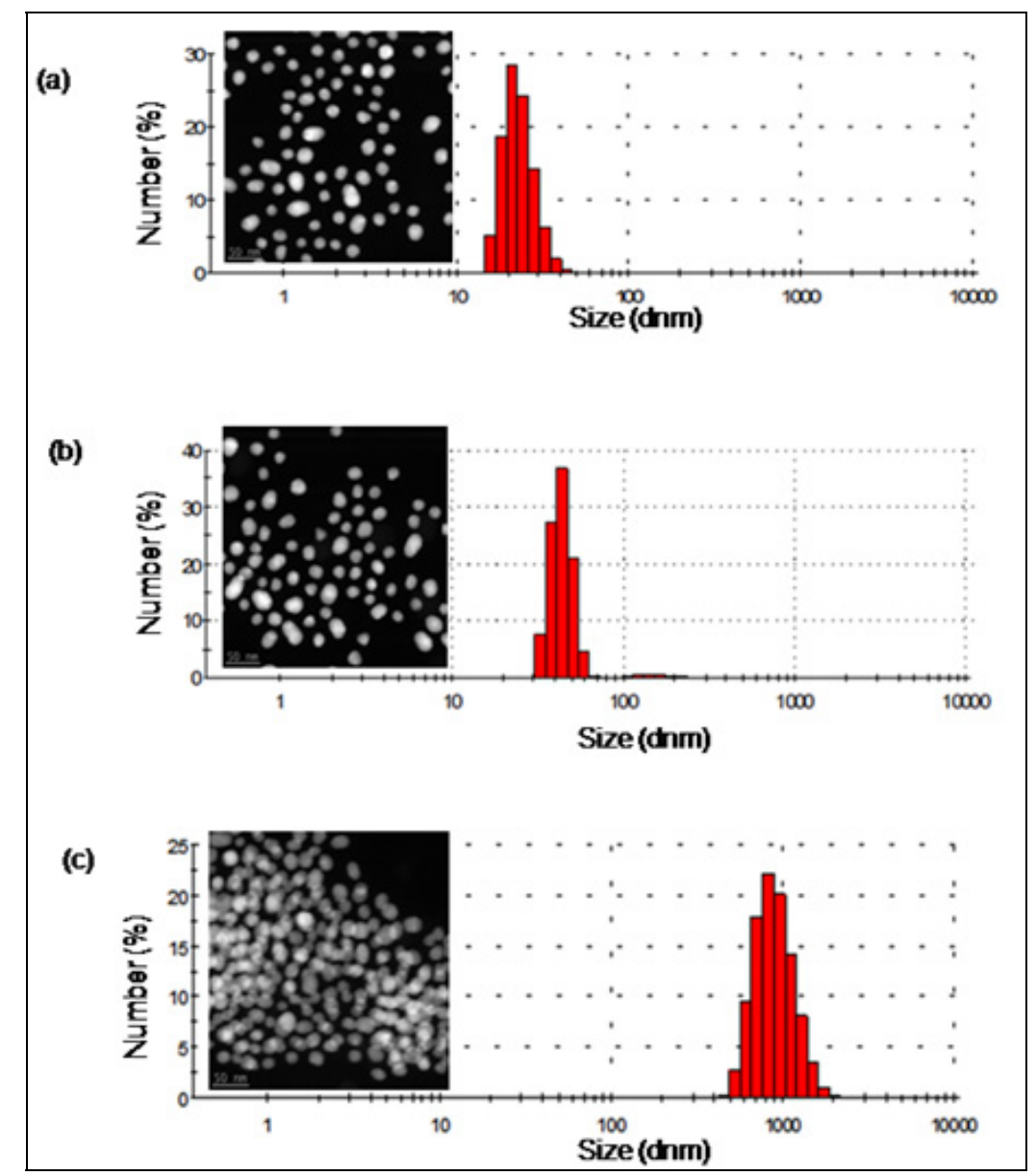

Figure 2. TEM images and Particle size histograms for size distribution analysis as obtained by Malvern Zetasizer (a) Glutamic acid capped gold nanoparticles (b) Antibody functionalized gold nanoparticles (c) Aggregated gold nanoparticles when used as tracer

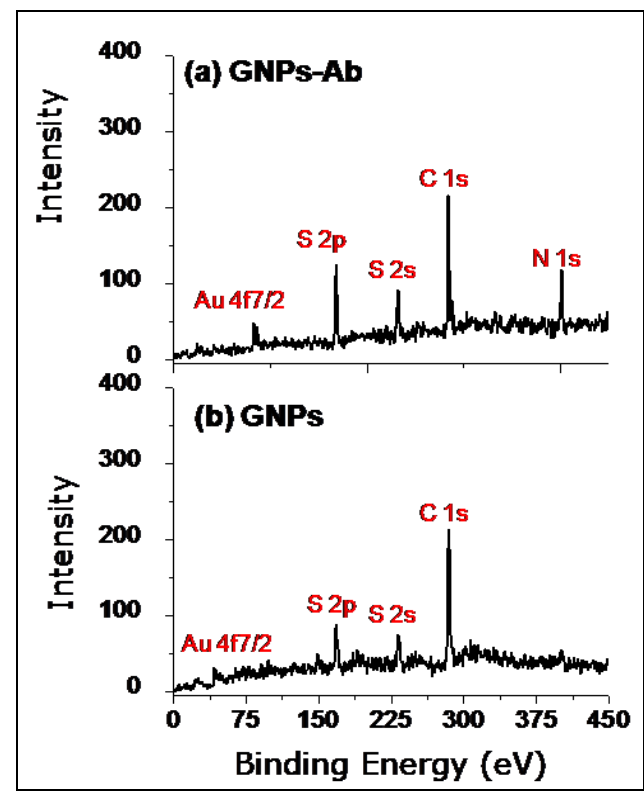

Figure 3. XPS spectra (a) Glutamic acid capped gold nanoparticles (b) Antibody functionalized gold nanoparticles 


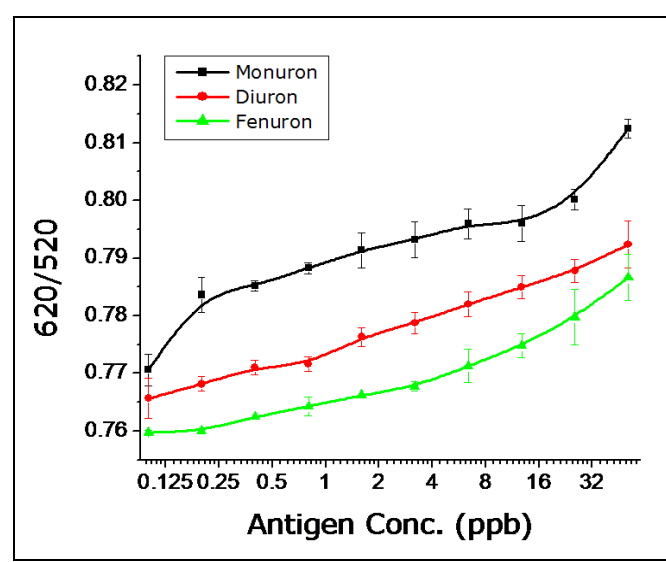

Figure 4. Aggregation profile (620/520 ratio) of gold nanoparticles when diuron, fenuron and monuron were used as antigen at different concentrations $(0.1 \mathrm{ppb}-50 \mathrm{ppb})$ 